\title{
In Vitro Investigation of the Cellular Toxicity of Boron Nitride Nanotubes
}

\author{
Lenke Horváth, ${ }^{\dagger, \neq}$ Arnaud Magrez, ${ }^{+, s, *}$ Dmitri Golberg, ${ }^{\perp}$ Chunyi Zhi, ${ }^{\perp}$ Yoshio Bando, ${ }^{\perp}$ Rita Smajda, ${ }^{\dagger}$ \\ Endre Horváth, ${ }^{\dagger}$ László Forró, ${ }^{\dagger}$ and Beat Schwaller, ${ }^{\ddagger} *$ \\ †Laboratory of Physics of Complex Matter (LPMC), Ecole Polytechnique Fédérale de Lausanne, 1015 Lausanne, Switzerland, ${ }^{\ddagger}$ Unit of Anatomy, Department of \\ Medicine, University of Fribourg, Route Albert-Gockel 1, CH-1700 Fribourg, Switzerland, ${ }^{S}$ Center for Research on Electronically Advanced Materials (CREAM), \\ Ecole Polytechnique Fédérale de Lausanne, 1015 Lausanne, Switzerland, and ${ }^{\perp}$ International Center for Materials Nanoarchitectonics (MANA), National Institute for \\ Materials Science (NIMS), Namiki 1-1, Tsukuba, Ibaraki 3050044, Japan
}

\begin{abstract}
$\mathrm{n}$ recent years, the enormous progress in nanotechnology and material sciences has stimulated the development and production of engineered nanomaterials (ENM), especially carbon nanotubes (CNTs). ${ }^{1}$ Owing to their unique physical and chemical properties, CNTs have been used in a wide range of applications from electronics, composites, catalyst support to many biological applications (e.g., separation, drug delivery, medical imaging). As a result, the quantity of tubular ENMs manufactured is ever-increasing, and it has raised considerable concern about the risk to human health and the environment because of their resemblance with highly toxic asbestos fibers.
\end{abstract}

First addressed for CNTs, the toxicity and biocompatibility of tubular ENMs remain controversial. In several in vitro studies employing different cell lines, cell types, and assays for toxicity evaluation, CNTs were shown to be cytotoxic and/or to induce inflammatory responses, while in a number of reports, CNTs were also found to be biocompatible when cultured with cells. ${ }^{2-5}$ This controversy arises very likely from the different methods of production, purification, and manipulation (by chemical or physical means) which yield CNTs with different morphology, defect, and surface properties as well as with the presence of impurities. These are known factors that dramatically influence the biological responses to ENMs.

Like CNTs, boron nitride nanotubes (BNNTs) are of significant interest to the scientific community. ${ }^{6,7}$ They are structurally very close analogues of CNTs, where $C$ atoms are fully substituted by alternating $\mathrm{B}$ and $\mathrm{N}$ atoms. ${ }^{8}$ They display far better thermal and chemical stabilities than their $C$ counterparts. Thus the BNNT usage is preferred, as far as nanotubebased device applications are expected at high temperatures and in chemically active and/or

ABSTRACT Nanotubes present one of the most promising opportunities in nanotechnology w a plethora of applications in nanoelectronics, mechanical engineering, as well as in biomedi technology. Due to their structure and some physical properties, boron nitride (BN) nanotuk (BNNTs) possess several advantages over carbon nanotubes (CNTs), and they are now commercia produced and used on a large scale. The human and environmental exposure to BN nanomaterial! expected to increase in the near future, and their biological responses need to be examined. Usi complementary assays, we have extensively investigated the effects of BNNTs on the viability a metabolic status of different cell types: on the one hand, the effects on cells present in the lu alveoli, and on the other hand, on human embryonic kidney (HEK) cells. Our results indicate th BNNTs are cytotoxic for all cell types studied and, in most cases, are more cytotoxic than CNTs in th pristine (p-CNT) and functionalized (f-CNT) form. However, the level of toxicity and the promine morphological alterations in the cell populations withstanding BNNT exposure are cell-tyr dependent. For instance, BNNTs induced extensive multinucleated giant cell formation macrophages and increased levels of eosinophilia in fibroblasts. Finally, our results point $t$ toxicity of tubular nanomaterials to be strongly correlated with the cellular accumulation enhanc for straight nanotubes.

KEYWORDS: MTT assay · DNA assay · FMCA assay · entanglement $\cdot$ tortuosity

hazardous environments. ${ }^{9}$ Although their use as vectors for drug delivery ${ }^{10}$ or MRI contrast agents is foreseen, ${ }^{11}$ the application of BNNTs in biomedicine remains largely unexplored. In particular, the interaction of BNNTs with living cells has not been addressed yet extensively. Ciofani et al. ${ }^{7,10}$ reported first on the biocompatibility with human neuroblastoma and muscle cells of polyethyleneimine- (PEI), polyL-lysine (PLL)-coated and uncoated BNNTS using complementary assays. ${ }^{12,13}$ Similarly, HEK and $\mathrm{CHO}$ cells are not affected by the presence of BNNTs in the culture medium up to a dose of $100 \mu \mathrm{g} / \mathrm{mL}^{14}$

Although the absence of cytotoxicity of BNNTs has been firmly stated in previous reports, the controversy over the toxic action of CNTs necessitates further validation of the existing results on BNNT cytocompatibility. In addition, cells from the
* Address correspondence to arnaud.magrez@epfl.ch, beat.schwaller@unifr.ch. 

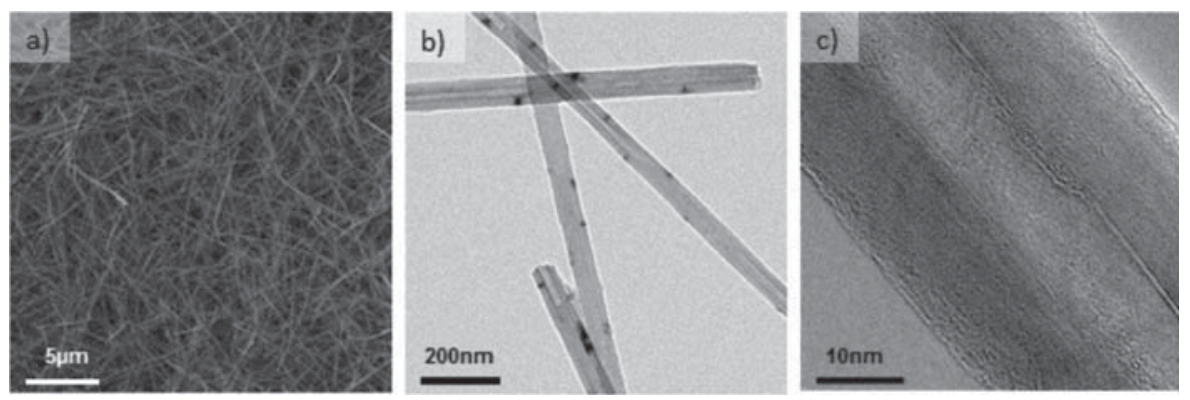

Figure 1. Scanning (a) and Transmission $(b, c)$ electron micrographs of multiwalled BNNTs.

lung have to be tested since human exposure to various nanomaterials is most likely to occur through inhalation and these nanomaterials arise in the form of aerosols and colloidal suspensions. Once particles are inhaled, cells of the pulmonary epithelium as well as resident macrophages will be exposed to BNNTs.

The importance of studying the health hazard of BNNTs, beyond their possible large-scale applications, relies on the fact that they are very good model systems. Their interaction with living cells can contribute to the understanding of toxicity of nanomaterials, in general, including that of asbestos.

In this study, we examined the in vitro cytotoxicity of BNNTs by using five complementary assays and by testing four different cell lines including human lung adenocarcinoma epithelial cells, murine alveolar macrophage cells, murine embryonic fibroblast cells, and human embryonic kidney (HEK) cells. Our results show BNNTs to be cytotoxic in a time- and dosedependent manner. Moreover, they induce modifications of the metabolic activity as well as of the cell morphology. However, the effect of BNNTs is strongly cell-type-dependent and is more pronounced in cells having high endocytic (phagocytic) ability like macrophages. Finally, the rather high toxicity of BNNTs for HEK cells observed in this study contradicts the previous observation of low toxicity. ${ }^{14}$ This indicates that one has to perform more detailed investigations before concluding on the cytocompatibility of BNNTs.

\section{RESULTS AND DISCUSSION}

Cytotoxicity Analyses. On the basis of the fact that nanotubes have morphological similarities with asbestos and inhalation of asbestos fibers is known to induce progressive fibrotic disease of the lung (asbestosis) and lung cancer, we explored the acute cytotoxicity of BNNTs (Figure 1) on lung epithelial cells (A549), alveolar macrophages (RAW 264.7), and fibroblast cells (3T3-L1). Human embryonic kidney cells (HEK293) were also exposed to BNNTs in order to compare the results with a previous study, where BNNT materials were produced and manipulated in different conditions. ${ }^{13}$

The effect of BNNTs on the proliferation and metabolic status of the cells was first investigated by the MTT assay, which is routinely used for these types of experiments and reports the combined effects of proliferation (cell number) and metabolic activity of cells. The average growth curves of A549, RAW 264.7, 3T3-L1, and HEK293 cells exposed to BNNTs $(2 \mu \mathrm{g} / \mathrm{mL}$ ) showed a decrease of the MTT signal as compared to untreated cells (Figure $2 \mathrm{a}-\mathrm{d}$ ). The toxic action of BNNTs already appearing after $48 \mathrm{~h}$ was time- and dose-dependent (Figure $2 \mathrm{e}-\mathrm{h}$ ). These results contradict previously reported data since, in our study, BNNTs exhibited a toxic action for HEK293 cells at a dose 5000 times lower than the one applied in the study of Chen et al. ${ }^{14}$ However, the authors performed the toxicity tests without the use of a dispersing agent to stabilize the suspension of BNNTs. The rapid aggregation of BNNTs within $1 \mathrm{~h}$ is likely to have prevented cells from being exposed to individual nanotubes. ${ }^{14}$ In contrast, we used a biocompatible surfactant yielding a suspension of individually dispersed nanotubes with long-term stability (Figures S1 and S2 in Supporting Information). Thus, HEK293 cells were exposed to well-dispersed BNNTs, and their toxicity was compared to other cell types. Clearly, HEK293 cells were the least impaired in their growth and their metabolic activity; BNNTs' effect was stronger for A549 and 3T3-L1 cells, and they were the most toxic for RAW 264.7 macrophage cells (Figure 2). The lowest and highest toxicities were found for cells exhibiting lower (HEK293) and higher (RAW 264.7) endocytic uptake capability, respectively. A similar correlation between the cell-type-dependent uptake ability and cytotoxicity has been observed before for other ENMs like CNTs. ${ }^{15}$

The time- and dose-dependent toxicity shown in Figure 2 revealed that BNNTs reduced more strongly the proliferation and the metabolic activity of all cell types than CNTs. The toxicity of BNNTs was higher at all concentrations and for all exposure times than that of CNTs, even when the surface of the CNTs was decorated with functional groups, previously shown to increase toxicity. ${ }^{16}$ Again, the lower sensitivity of HEK293 cells toward all tested ENMs hints that the cellular internalization is a key parameter for the acute toxicity of ENMs. Although BNNTs have similar dimensions as CNTs, they are straighter particles, and we hypothesize that these rod-like structures more easily transverse the cell membrane than curly CNTs that are 

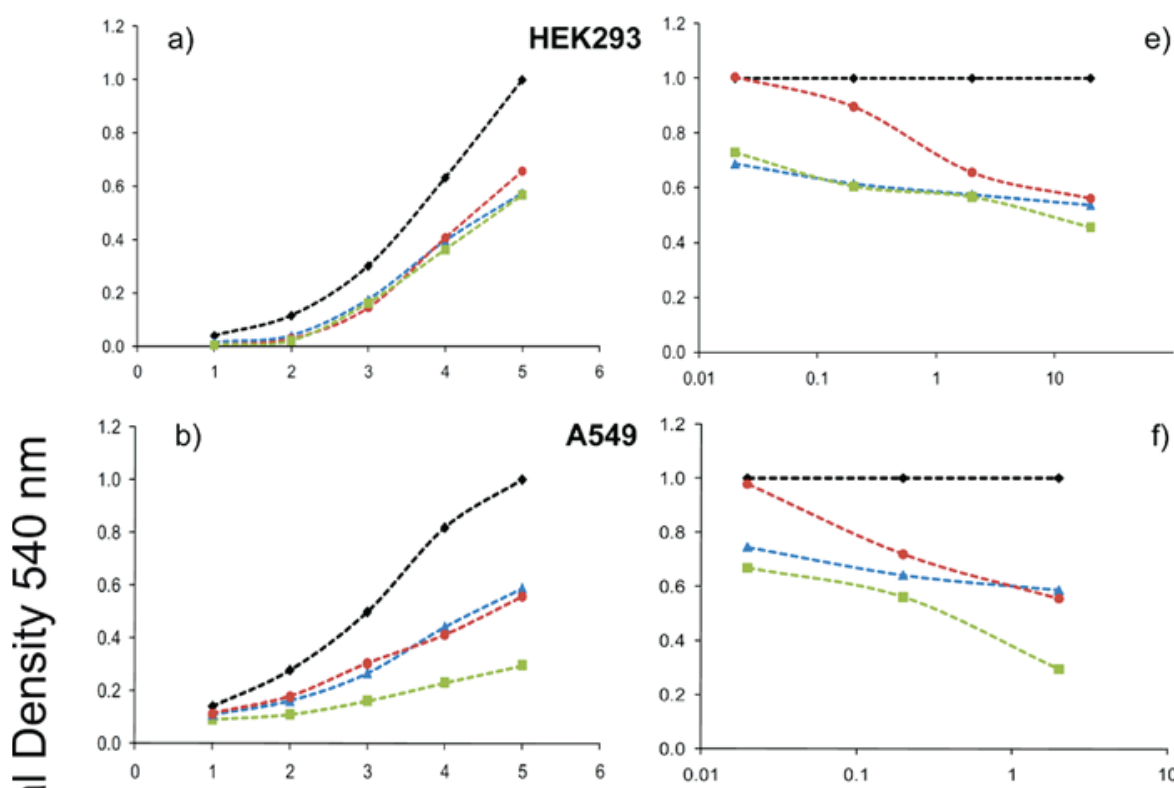

A549
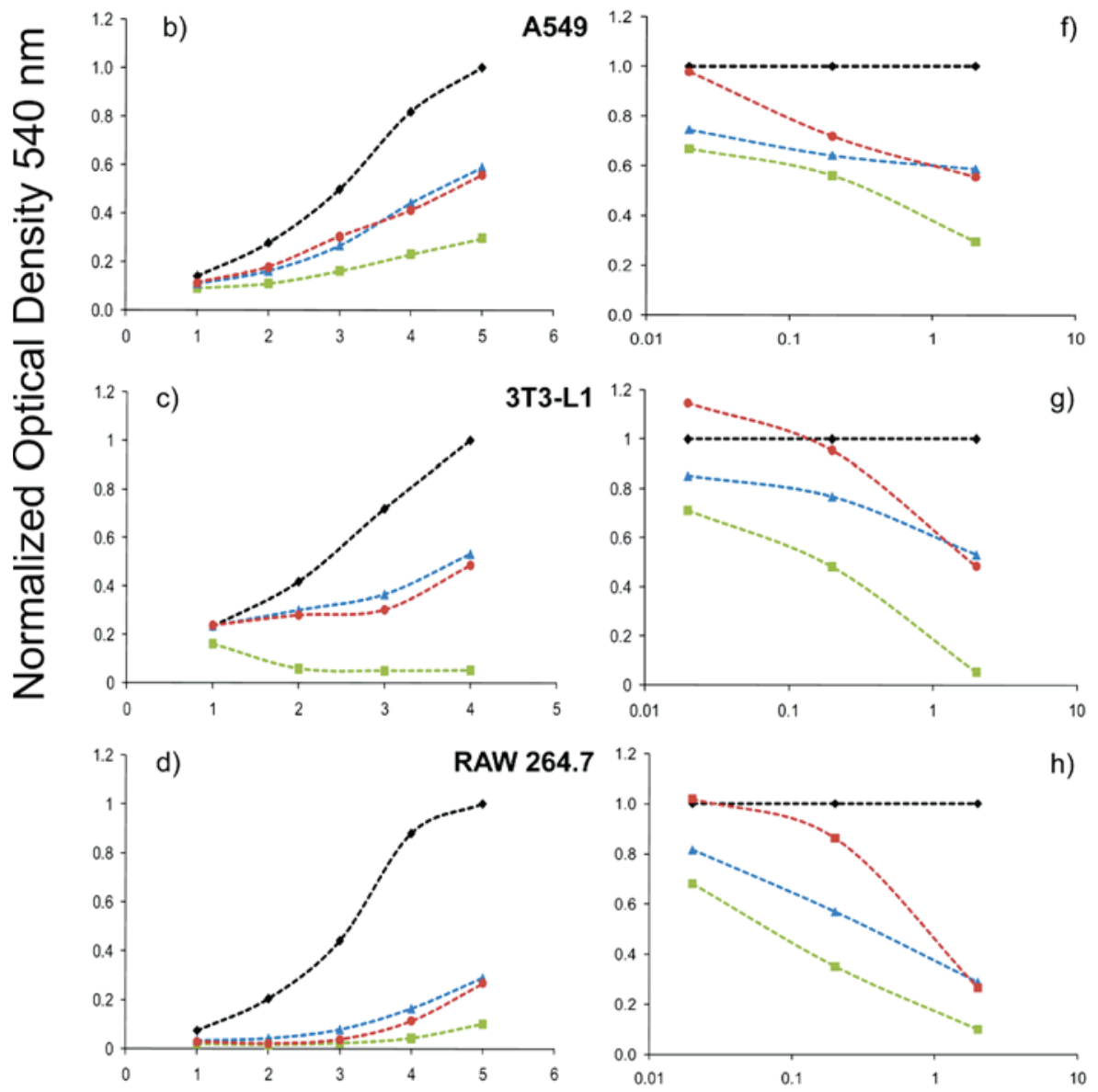

Days of exposure

Nanotube concentration $(\mu \mathrm{g} / \mathrm{ml})$

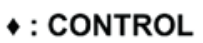

$\bullet: \mathrm{p}-\mathrm{CNT}$

$\Delta$ : f-CNT

- : BNNT

Figure 2. MTT assay: (a-d) representative normalized growth curves of HEK293, A549, 3T3-L1, and RAW 264.7 cells exposed to $\mathrm{p}-\mathrm{CNT}$, $\mathrm{f}-\mathrm{CNT}$, and BNNT at a $2 \mu \mathrm{g} / \mathrm{mL}$ dose. Control experiments were performed in medium containing $2 \mu \mathrm{g} / \mathrm{mL}$ Tween 80 . (e-h) Normalized dose-dependent toxicity of HEK293, A549, 3T3-L1, and RAW 264.7 cells treated with p-CNTs, f-CNTs, and BNNTs for $4(\mathrm{~g})$ and $5(\mathrm{e}, \mathrm{f}, \mathrm{h})$ days. The optical density is proportional to the number of living cells.

prone to entanglement. Entangled CNTs, initially absent in the medium-containing suspension added to the cells, were formed during the incubation period and could be detected in various amounts in the culture dishes, most notably the ones formed by pristine CNTs (p-CNTs) and to a lesser extent by functionalized CNTs (f-CNTs) (Figure 3). Also, on the cell surface of fibroblasts, entangled CNTs were detected (Figure 4a). It is plausible that these entangled aggregates have limited cellular internalization ability in comparison to the rod-like
BNNTs, which are found in some cases to pierce the membrane from various directions (Figure 4b).

We further characterized the cellular toxicity by fluorometric DNA assay and fluorometric microculture cytotoxicity assay (FMCA) as MTT was previously reported to be prone to artifacts in the case of tubular ENMs. ${ }^{12,17}$ We performed these complementary assays on the least and the most sensitive lung A549 epithelial cells and RAW 264.7 macrophages, respectively (Figure 5). In contrast to the MTT assay, the DNA method measures rather directly 


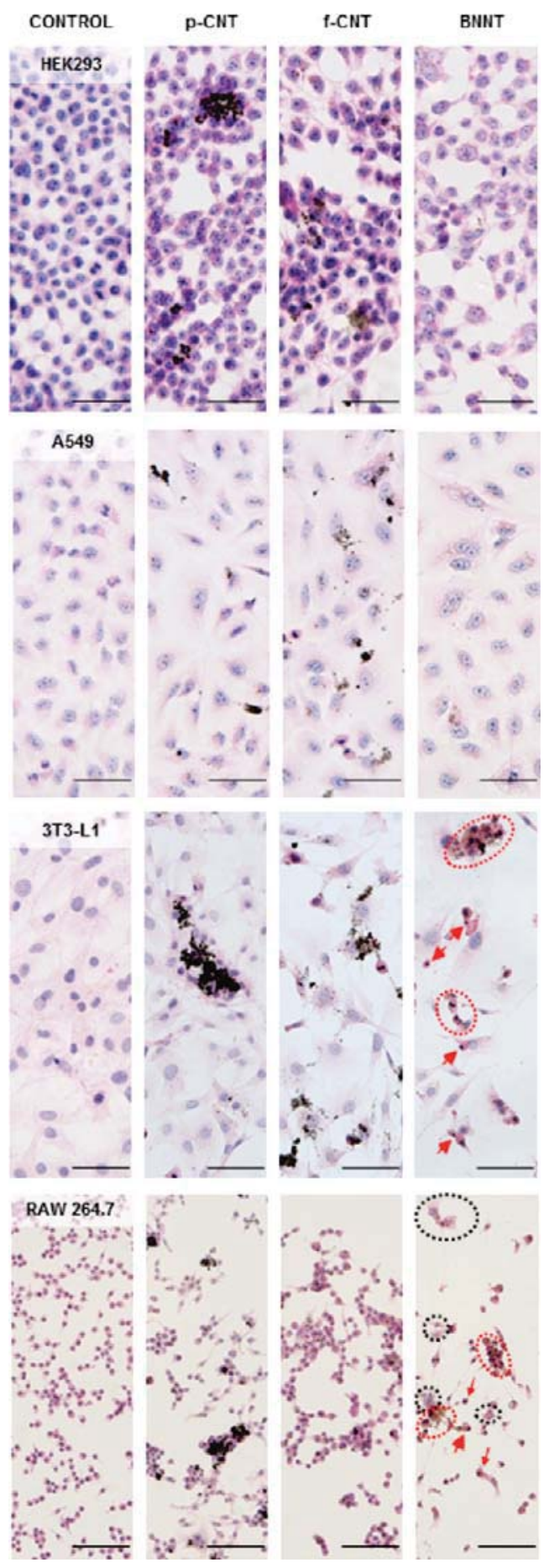

Figure 3. Cytopathological analyses of HEK293 kidney cells (first row), A549 epithelial cells (second row), 3T3-L1 fibroblasts (third row), and RAW 264.7 macrophages (fourth row) not treated with ENMs (control, first column) and treated for 4 days with approximately $2 \mu \mathrm{g} / \mathrm{mL}$ of $\mathrm{p}-\mathrm{CNT}$ (second column), f-CNT (third column), and BNNT (fourth column). BNNT-treated RAW 264.7 and 3T3-L1 cells revealed characteristic alterations in morphology. These included disrupted cell-cell contacts leading to a more rounded appearance, due to cell retraction (eosinophilia). Consequently, the cytoplasmic staining was stronger (red circles), and cells with picnotic nuclei were present (red arrows). In addition, large multinucleated cells (black circles) undergoing frustrated phagocytosis were observed in the RAW 264.7 macrophages. Scale bars are $50 \mu \mathrm{m}$.
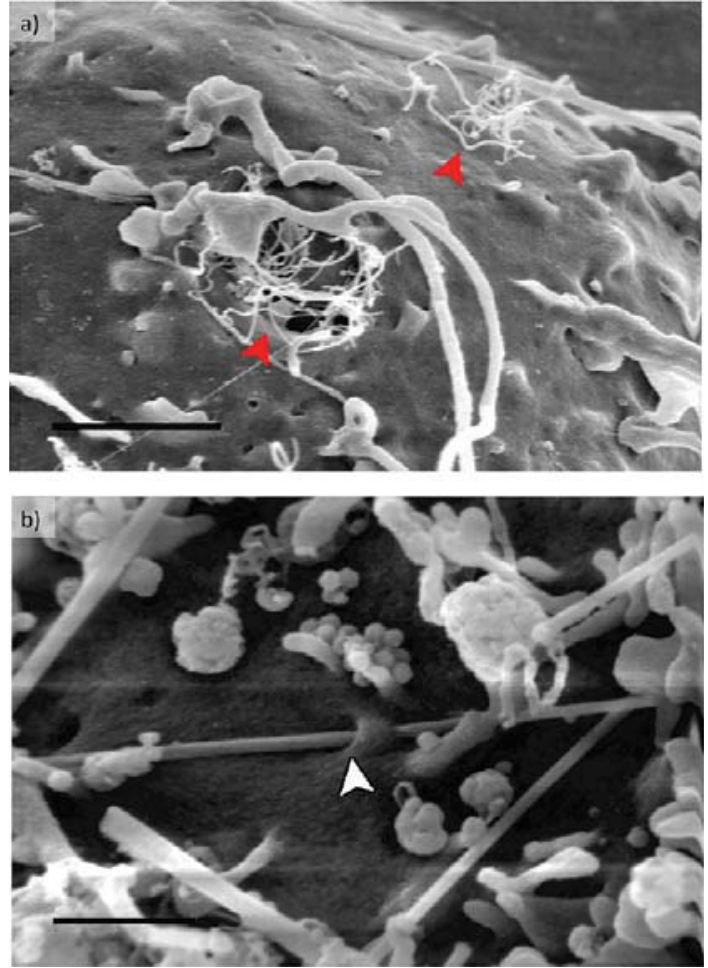

Figure 4. Scanning electron micrographs of (a) f-CNT exposed 3T3-L1 fibroblasts and (b) BNNT-exposed RAW 264.7 cells after 2 and 4 days, respectively; scale bars are $2 \mu \mathrm{m}$ (a) and $0.5 \mu \mathrm{m}$ (b). Entangled carbon nanotubes are found on the cell surface (red arrowheads) and have limited internalization, while BNNTs were found to pierce the plasma membrane of the cells (white arrowhead).

the cell number by quantifying the amount of DNA per sample. FMCA is an indirect measurement of cell viability by the assessment of the esterase activity of living cells having an intact cell membrane. Qualitatively similar results were obtained with all three methods (MTT, DNA, FMCA) and in both cell lines. The cell number/ viability decreased in an ENM concentration-dependent manner for the three types of materials. Generally, the order of the toxic action of the nanotubes was the following: BNNTs $>\mathrm{f}-\mathrm{CNTs} \geq \mathrm{p}$-CNTs. While this ranking was clearly observed in A549 cells with all three methods, the high toxicity of all ENMs at 2 and $20 \mu \mathrm{g} / \mathrm{mL}$ in RAW 264.7 macrophages precluded a "precise" ranking of toxicity. Both fluorometric assays confirmed the higher sensitivity of RAW 264.7 macrophages as compared to A549 cells for all tested ENMs. Already at $2 \mu \mathrm{g} / \mathrm{mL}$, a substantial loss in the order of $60-80 \%$ (depending on the type of assay) of macrophage cell number and/or macrophage mitochondrial activity (Figure $5 d-f$ ) was detected, while the decrease was limited to about 30\% when A549 epithelial cells were exposed to a 10 times higher ENM concentration (Figure 5a,b).

Detection of Morphological Alterations by Light and Scanning Electron Microscopy Imaging. Besides testing the global effects of the ENMs on cell proliferation/viability, we examined the morphological changes caused by the 

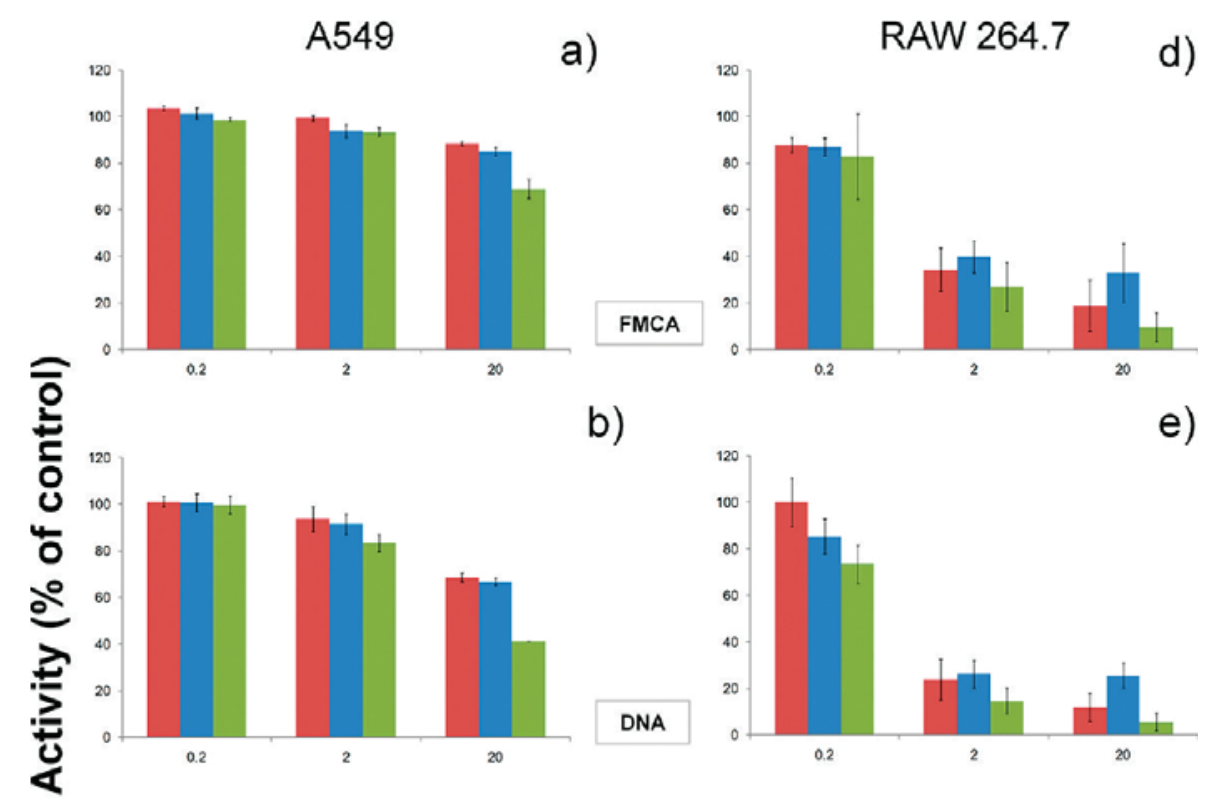

b)

e)
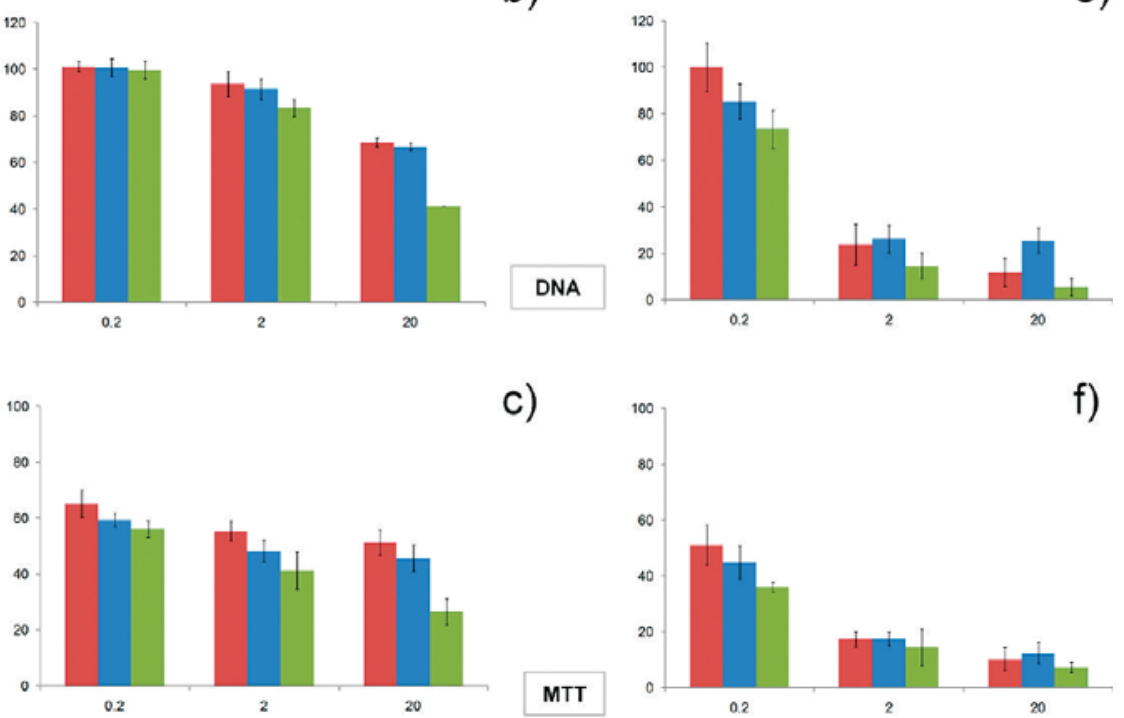

\section{Nanotube concentration $(\mu \mathrm{g} / \mathrm{ml})$}

$$
\bullet: \mathrm{p}-\mathrm{CNT} \quad \triangle \text { : f-CNT }
$$

Figure 5. Effect of nanomaterials on A549 (a-c) and RAW 264.7 ( $d-f$ ) cells determined by FMCA assays (a,d), DNA assays (b,e), and MTT assays (c,f). Measurements were performed after 5 days of exposure to $0.2,2$, and $20 \mu \mathrm{g} / \mathrm{mL}$ nanomaterials dispersed in $20 \mu \mathrm{g} / \mathrm{mL}$ Tween 80. Cells were treated with p-CNTs, f-CNTs, and BNNTs. Mean \pm standard deviation values from three independent experiments are shown. For each condition and type of assay, the value for untreated control cells was defined as $100 \%$.

ENMs by light and scanning electron microscopy (SEM). The four cell types were treated for 4 days with 2 and $20 \mu \mathrm{g} / \mathrm{mL}$ ENMs for the two microscopic methods, respectively. At a global level, the cell density decreased in ENM-treated cells, when compared to untreated (control) cells (Figure 3). The order of reduction in cell density provoked by the ENMs was in good agreement with the results of the quantitative methods on cell proliferation/viability (Figures 2 and 5). A549 and HEK293 cells were the least affected, and qualitatively no differences were observed with respect to morphological hallmarks characteristic for cell death and cell damage, including the following features: loss of cell/cell contacts between neighboring cells, cytoplasm retraction with eosinophilia, shrunken (picnotic) nuclei, and multinucleated giant cells as previously reported. ${ }^{18}$ The density of ENM-treated macrophages (RAW 264.7) and fibroblasts (3T3-L1) was considerably lower in cells treated with $\mathrm{p}$ - and
$\mathrm{f}$-CNT and even lower in BNNT-treated cells. While clear morphological alterations were rarely found in ENMtreated A549 and HEK293 cells, distinct changes were observed in RAW 264.7 and 3T3-L1 cells, detectable already on low-magnification images, most notably in BNNT-treated cells (Figure 3). In both cells types, cell/ cell contacts were disrupted often leading to a more rounded appearance, the staining of the cytoplasm was stronger due to cell retraction (eosinophilia), and in addition to a shrinkage of nuclei, few large, multinucleated cells undergoing frustrated phagocytosis were observed in RAW 264.7 macrophages. At higher magnification, a clear accumulation of intracytoplasmic nanotubes inside macrophages (Figure $6 a, b$ ) and fibroblasts (Figure $6 c$ ) indicated that a substantial part of needle-shaped BNNTs with a length clearly shorter than the cell diameter was taken up and was localized inside the cells. An intracellular localization of BNNTs in treated cells had been previously demonstrated for 

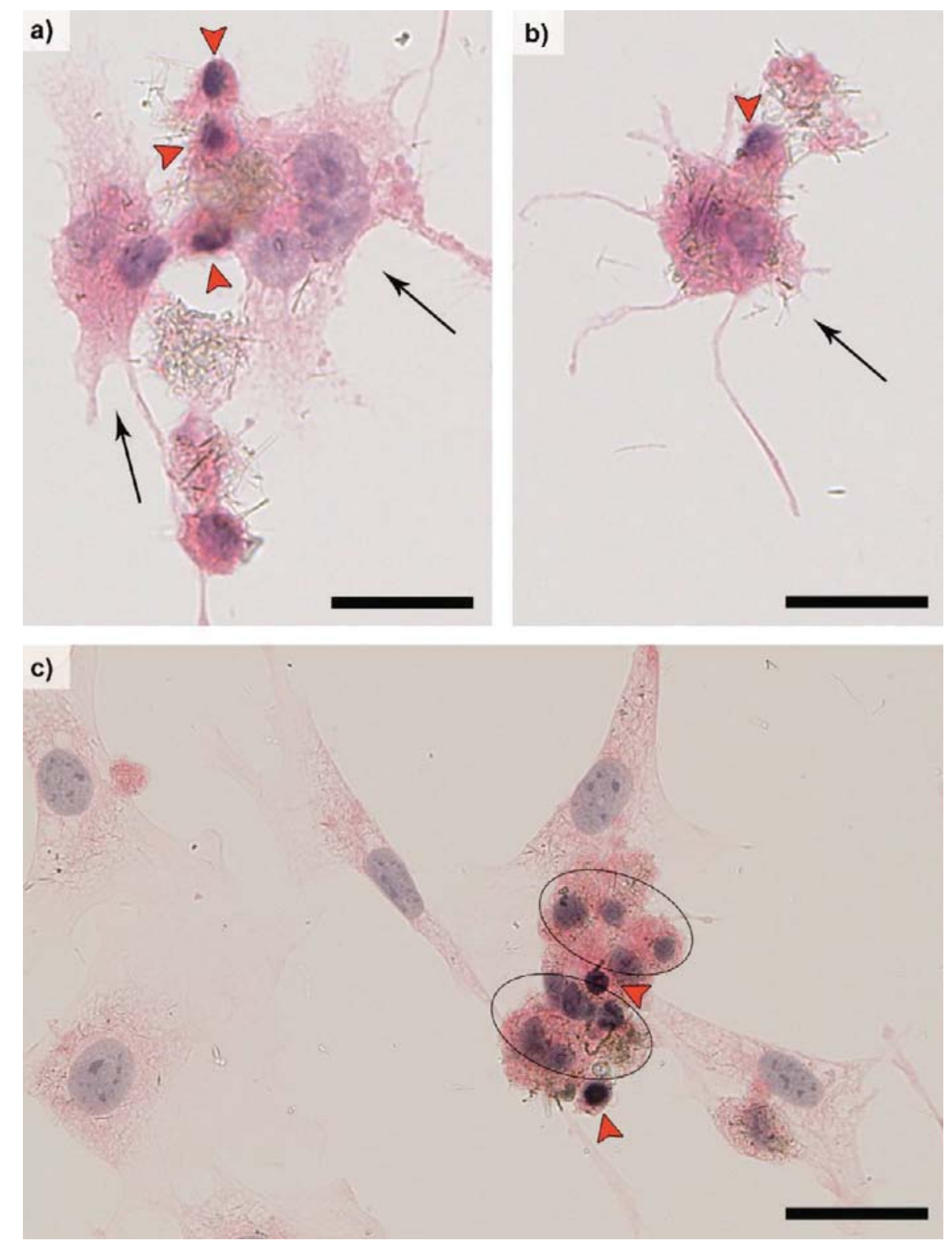

Figure 6. Typical morphological alterations after treatment with $2 \mu \mathrm{g} / \mathrm{mL}$ BNNTs. RAW 264.7 cells (a,b): multinucleated giant cells engulfed large amounts of nanotubes (arrows) surrounded by strongly stained eosinophilic cells with shrunken nuclei (red arrowheads). 3T3-L1 cells (c): group of eosinophilic fibroblast cells with retracted cytoplasm (black ovals) and two cells with strongly condensed (picnotic) nuclei (red arrowheads). Also two apparently healthy cells (left) show an accumulation of BNNTs in the cytoplasm. The scale bars correspond to $20 \mu \mathrm{m}$. In order to visualize the engulfed BNNTs, the focus was centered on the level of the nuclei of the well-attached cells. The strongly eosinophilic cells (arrowheads) in the images are slightly above the plane of focus and appear fuzzy.

SH-SY5Y neuroblastoma cells and $\mathrm{C} 2 \mathrm{C} 12$ muscle cells. ${ }^{10,13}$ In parallel to the intracytoplasmic accumulation of ENMs in the more susceptible RAW 264.7 and 3T3-L1 cells, also the percentage of cells with morphological alterations was higher than that in the more resistant A549 and HEK293 cells. Thus, in the former two cell types, we also determined in a semiquantitative way the percentage of cells, among the still viable cells after 4 days of ENM (f-CNTs and BNNTs) exposure, showing eosinophila (rounded, isolated cells) or cells with picnotic nuclei. For ENM-exposed macrophages, we additionally determined the percentage of multinucleated giant cells (Figure 7). The morphological changes in the presence of $\mathrm{f}$-CNTs were generally less prominent than after BNNT treatment. Among the BNNT-treated RAW 264.7 macrophages, almost 50\% showed signs of damage: approximately $15 \%$ were giant multinucleated cells, $30 \%$ had their cytoplasm retracted, and a low number of cells (2\%) had picnotic nuclei. In f-CNTs treated macrophages, the proportion of cells having the above-described alterations was similar, but the overall percentage of affected cells was reduced to less than $20 \%$ (Figure 7a). The high proportion of giant cells is a clear signature of an inflammatory 
response elicited by ENMs; in untreated control cells, almost no giant cells were detected. For the fibroblasts,

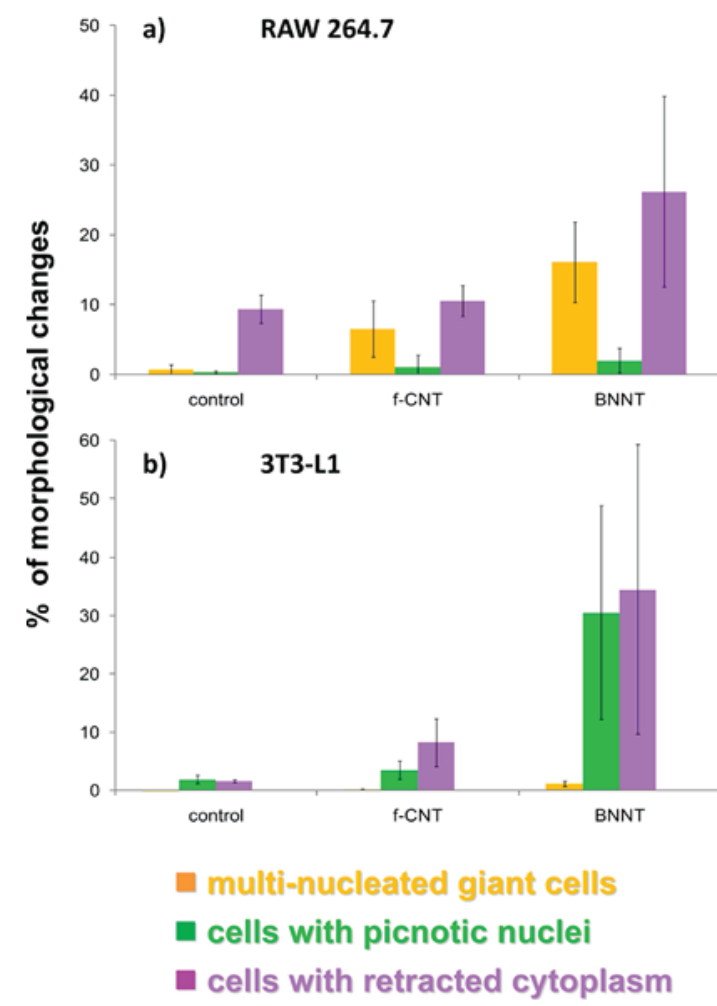

Figure 7. Quantification of morphological changes determined from optical micrographs for (a) RAW 264.7 macrophages and (b) 3T3-L1 fibroblasts in untreated (control) and treated cells exposed to $2 \mu \mathrm{g} / \mathrm{mL}$ of f-CNTs and BNNTs for 4 days. Mean \pm standard deviation values from three independent experiments are shown.
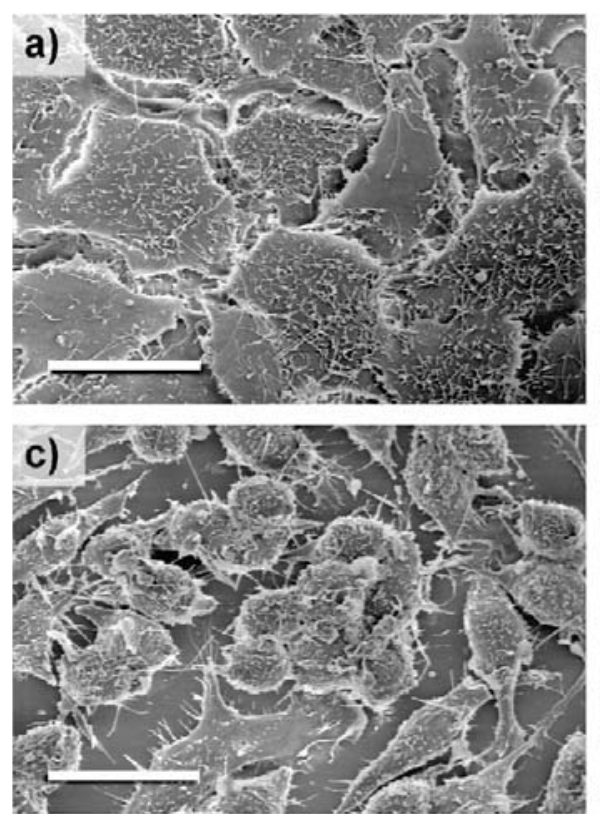

besides cells with cytoplasmic retraction, the large proportion of cells with picnotic nuclei was the hallmark of morphological changes seen in this cell type. The total percentages of damaged cells reached approximately $70 \%$ for BNNTs and were only in the order of $10 \%$ for f-CNTs (Figure 7b). In comparison to the macrophages, almost no multinucleated giant cells were detected in the ENM-treated fibroblasts. These results indicated that differences existed with respect to cell damages in different cell types; that is, giant cell formation was induced in inflammatory cells like macrophages, likely as a result of nanomaterial phagocytosis, while in cells that are not inherently specialized for foreign material clearance, but for extracellular matrix production like fibroblasts, alterations such as increased eosinophilia and picnosis were more pronounced.

Since part of the nanomaterials was also attached to the surface of exposed cells and fibers (e.g., asbestos) can exert their cytotoxic function by activating signaling pathways by attaching to surface receptors, the distribution of BNNTs on the cell surface of two selected cell types, epithelial cells (A549) and macrophages (RAW 264.7), was examined by SEM. The surface characteristics of untreated epithelial cells and macrophages consisted of microvilli (Figure 8a) and short cytoplasmic processes (pseudopodia; Figure 8c), respectively.

The density of BNNT-treated and control epithelial cells reached a near-confluent state, remained flat, strongly adherent to the cell support, and had a polygonal shape (Figure 3). No dramatic global morphological alterations occurred in BNNT-treated A549 cells; in some cases, a rearrangement of microvilli on
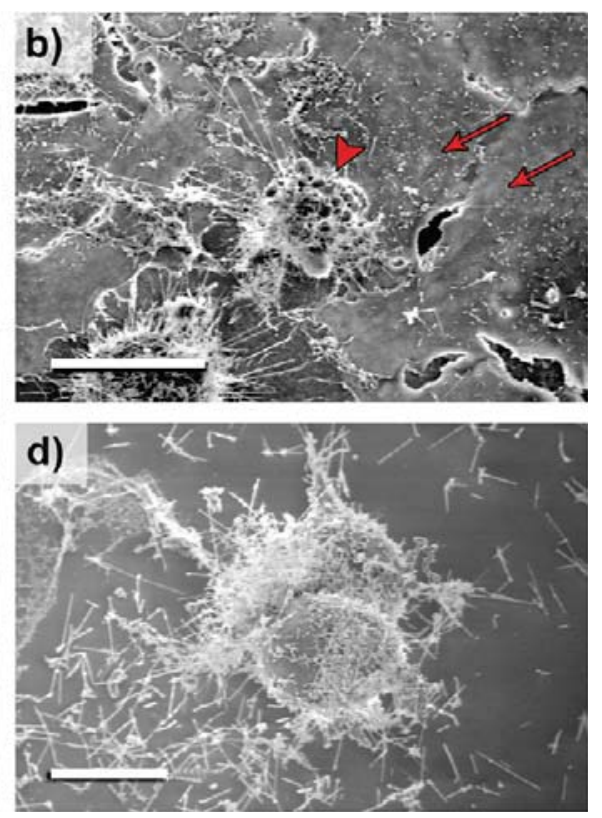

Figure 8. Scanning electron micrographs of A549 and RAW 264.7 cells exposed to $20 \mu \mathrm{g} / \mathrm{mL}$ BNNTs for 4 days. Untreated control cells of A549 (a) and RAW 264.7 (c) have a large number of microvilli and pseudopodia on their surfaces, respectively. (b) Treated A549 cells undergo rearrangement of microvilli (arrows), some cells also undergo blebbing (arrowhead); (d) BNNTs remained well-dispersed, both on the surface of RAW 264.7 cells, but also attached to the Petri dishes, confirming the longterm stability of the suspension; scale bars are $20 \mu \mathrm{m}(\mathrm{a}-\mathrm{c})$ and $10 \mu \mathrm{m}(\mathrm{d})$. 
the surface was apparent that resulted in some "smooth" areas and areas with irregularly distributed particles. Some cells underwent rounding, detachment, and surface blebbing (Figure 8b). RAW 264.7 macrophages were either spindle-shaped or, more often, had a spherical morphology, depending on the degree of attachment to the cell substrate. On the surface, cytoplasmic extensions in the form of pseudopodia or ruffles were visible (Figure $8 \mathrm{c}$ ). In the BNNT-treated macrophages, many nanotubes bound to the cell surface and covered the cells rather homogeneously (Figure 8d). Thus, besides the light microscope images, which yielded information on the morphological changes occurring inside ENM-treated cells, the high-resolution SEM images also revealed subtle ultrastructural modifications of the cell surface upon ENM exposure, in particular, in A549 epithelial cells. How these changes might be linked to the mechanisms leading to cytotoxicity remains to be investigated.

Comparison of Results with Previous Studies. The low cytotoxicity and thus the rather good biocompatibility of BNNTs reported before clearly contradict the results presented in this study. The major difference is the morphology and size distribution of the BNNTs tested in other studies. To evaluate the cytotoxic risk potential of BNNTs, Ciofani and co-workers ${ }^{7,10,12,13,19}$ used materials produced by solid-state chemistry, based on ball-milling and annealing of BN powders. This process yields BNNTs that are, on average, more than 10 times shorter than those employed in the present study. Moreover, transmission electron micrograph images clearly show BNNTs used by Ciofani et al. to have very jagged edges and rough surfaces, ${ }^{7,10}$ and when coated with polyethyleneimine (PEl), glycolchitosan (GC), or poly-L-lysine to enhance their solubilization, BNNT particles appear almost isotropic. ${ }^{13}$ Evidently, the shape and geometry is a crucial parameter for the cytotoxicity of ENMs. ${ }^{16,18}$ In general, long and fiber-shaped materials show higher acute cytotoxicity than their low aspect ratio counterparts. Moreover, the intracellular uptake of BNNTs observed by Ciofani and co-workers or seen in our study in apparently healthy cells (Figure $6 \mathrm{c}$ ) may not lead to immediate (acute) cytotoxicity, but it may result in an inflammatory response, ${ }^{20}$ aberrant mitosis, processes that in the long term may lead to tumorigenesis.

The contradiction between the cytotoxicity studies of BNNTs could, at least in part, also be linked to the unconventional MTT assay employed by Ciofani and co-workers in the earlier studies. ${ }^{7}$ In particular, after culturing with BNNTs, cells were trypsinized (removed from the substrates on which they are cultivated) and replated onto new cell culture dishes before adding the dye for the MTT assay. Thus, potentially damaged and fragile cells, possibly not withstanding the trypsinization process, were likely not taken into account for the cytotoxicity evaluation of BNNTs.

The toxic action of BNNTs was as well assessed when incorporated within a polymer or apatite matrix to enhance the performance of biocompatible implants. ${ }^{21,22}$ The growth of osteoblasts and macrophages on the BNNT-containing composite material was not negatively affected as the percentage of viable cells on composite was even higher than on the BNNT-free polymer. In this study, BNNTs were again shorter $(<6 \mu \mathrm{m})$ than those we employed $(\sim 10 \mu \mathrm{m})$, and the content of BNNTs in direct cell contact that might be taken up by the cells by endocytosis is probably very low. Therefore, BNNTs exhibit low cytotoxicity when embedded in a matrix. However, our study substantiates the potential hazard of individual BNNTs if released from the matrix, intentionally injected into the body or taken up by the airways.

\section{CONCLUSIONS}

Our study clearly indicates that BNNTs are cytotoxic ENMs in vitro already at low concentration in the investigated cell lines. Although previous reports using BNNTs with different particle characteristics or BNNTs embedded in a polymer matrix concluded that their BNNTs showed cytocompatibility, the three viability assays used in this study point beyond any doubts to a drastic inhibition of cell proliferation as well as to a strong impairment of the metabolic activity of the four cell types tested using long and individually dispersed BNNTs. Cytopathological observations showed BNNTs to induce also serious cellular alterations, which are characteristic for damaged cells prone to cell death. On the other hand, the correlation between the sensitivity and the endocytic activity of the cell as well the noticeable difference in the toxicity between curly CNTs undergoing entanglement that limits internalization and straight BNNTs penetrating easily the cell membrane corroborate the cellular uptake of ENMs to be one of the crucial steps of their toxic action. Finally, it is of utmost importance to further evaluate the toxicity of BNNTs, particularly in vivo, before intensifying their use especially in biomedical applications.

\section{MATERIALS AND METHODS}

Synthesis and Characterization of Nanotubes and Preparation of Nanomaterial Stock Solutions. Multiwalled BNNTs were produced by a chemical vapor deposition (CVD) method using boron and magnesium oxide as precursors (so-called BOCVD); the detailed process was reported elsewhere. ${ }^{23-27}$ The as-grown BNNTs were purified by high-temperature annealing in argon and acid washing to remove oxide impurities and catalyst particles. The 
BNNTs had typical diameters of less than $80 \mathrm{~nm}$ (on average $\sim 50 \mathrm{~nm}$ ) and a length of up to several micrometers (on average $\sim 10 \mu \mathrm{m})$. The chemical purity of nanotubes was confirmed by electron energy loss (EELS) and energy-dispersion X-ray (EDX) spectroscopy inside TEM. Only B and N K-edges at 188 and $403 \mathrm{eV}$, respectively, were detected in the EEL spectra at an atomic ratio of $\sim 1.0$. No metal or other impurities were found in the product, as evidenced by the EDX spectra.

Multiwalled CNTs were produced by CVD of acetylene $\left(\mathrm{C}_{2} \mathrm{H}_{2}\right)$ over $\mathrm{Fe}_{2} \mathrm{Co}$ supported by $\mathrm{CaCO}_{3}$ at $660{ }^{\circ} \mathrm{C}$. During a purification process, CNTs were dispersed for $15 \mathrm{~min}$ in a sonication bath in a solution of $1 \mathrm{M} \mathrm{HCl}$ and then incubated overnight at room temperature (RT). After filtration, materials were washed with distilled water and dried at $150^{\circ} \mathrm{C}$ overnight. CNTs were further annealed at high temperature to remove any chemical groups bonded to the surface $\left(1000{ }^{\circ} \mathrm{C}\right.$ for $2 \mathrm{~h}$ under dynamic vacuum). To achieve surface filament modifications yielding functionalized CNTs (f-CNTs), purified CNTs were dispersed in $1 \mathrm{M}$ nitric acid and incubated overnight at RT. Other details on the production and purification of CNTs were reported before. ${ }^{16}$ CNTs exhibited an average diameter of $20 \mathrm{~nm}$ and an aspect ratio ranging from 80 to 90 . The chemical composition of CNTs was analyzed by inductively coupled plasma mass spectrometry (Elan 6100). CNTs had carbon content higher than 99.2 atom \%. While no oxygen could be detected on the surface of $\mathrm{p}$-CNTs, the presence of functional groups such as $\mathrm{COOH}, \mathrm{OH}$, and $\mathrm{C}=\mathrm{O}$ groups on the surface of $\mathrm{f}$-CNTs has been confirmed by XPS with a measured oxygen content close to 1 atom \%.

Tween 80 (polyoxyethylene sorbitan monooleate; Sigma P4780), a nonionic surfactant used widely in food products, pharmaceutical preparations, and cosmetics, ${ }^{28}$ was used as the dispersing agent. This substance has been previously used to disperse and to stabilize nanomaterial suspensions including CNTs in several studies. ${ }^{18,29}$ All solutions were prepared as aqueous stock solutions by several consecutive sonication and stirring steps and contained $200 \mu \mathrm{g} / \mathrm{mL}$ nanoparticles and $200 \mu \mathrm{g} / \mathrm{mL}$ Tween 80 . For cell exposure experiments, stock solutions were diluted in cell culture medium to final concentrations of $0.02,0.2,2$, and $20 \mu \mathrm{g} / \mathrm{mL}$.

Cell Culture and In Vitro Cytotoxicity Measurements. Four different cell lines were used for the experiments: A549 cells, human type II lung epithelium cells, previously used for lung toxicity assays, ${ }^{30-33}$ RAW 264.7 mouse macrophage cells, 3T3-L1 mouse embryonic fibroblast cells, and HEK293 human embryonic kidney cells. The first three cell lines were obtained from American Type Culture Collection (ATCC, USA, catalogue numbers: CCL-185, TIB-71, and CL-173, respectively), while HEK293 cells were kindly provided by Prof. J. Loffing, University of Zurich, Switzerland. The cells were cultured in RPMI-1640 (Gibco), except HEK293 cells in DMEM (Gibco) supplemented with $10 \%$ fetal calf serum and antibiotics $(100 \mathrm{U} / \mathrm{mL}$ penicillin; $100 \mu \mathrm{g} / \mathrm{mL}$ streptomycin; Gibco). They were maintained in a humidified atmosphere containing $5 \% \mathrm{CO}_{2}$ at $37{ }^{\circ} \mathrm{C}$ and passaged at $80 \%$ confluency. Cells were seeded in 96 -well culture plates. After an overnight incubation (once adhesion was verified), $100 \mu \mathrm{L}$ of fresh medium containing the corresponding amount of nanomaterials (NM) was added to the cells. Cells were exposed to $0.02,0.2$, and $2 \mu \mathrm{g} / \mathrm{mL}$ NM (with $2 \mu \mathrm{g} / \mathrm{mL}$ Tween 80$)$ and/or $20 \mu \mathrm{g} / \mathrm{mL}$ nanomaterials $(20 \mu \mathrm{g} / \mathrm{mL}$ Tween 80 ) for up to 5 days, in parallel to control samples that contained either 2 or $20 \mu \mathrm{g} / \mathrm{mL}$ Tween 80 , respectively. Each experiment was repeated at least three times with a minimum of three replicates of the same material and NM concentration.

MTT Assay. Cell proliferation was evaluated by the MTT (3-(4,5-dimethylthiazol-2-yl)-2,5-diphenyltetrazolium bromide) assay (thiazolyl blue tetrazolium bromide; M5655, Sigma). The assay is based on the accumulation of dark blue formazan crystals inside living cells after their exposure to $M T$, which is measured photometrically by the addition of dimethylsulfoxide (DMSO, $100 \mu \mathrm{L} /$ well) that permeabilizes the cell membrane and results in the liberation and solubilization of the formazan crystals. The formazan concentration was finally quantified using an ELISA plate spectrophotometer by measuring the absorbance at $540 \mathrm{~nm}$ (Dynatec MRX, Dynatec Produkte AG, Switzerland).

Fluorometric DNA and Fluorometric Microculture Cytotoxicity Assay. The number/viability of cells was further investigated by two other methods: the fluorometric DNA assay ${ }^{34}$ and the fluorometric microculture cytotoxicity assay (FMCA). ${ }^{35}$ In the former, the amount of DNA per sample (e.g., in a well of a 96-well plate) was quantitatively determined and was found to be directly proportional to the number of cells. At various time points, the culture medium was removed from the cell samples, attached cells were washed with phosphate-buffered saline (PBS) and frozen at $-80^{\circ} \mathrm{C}$. After the first freeze/thaw cycle, $100 \mu \mathrm{L} /$ well of double-distilled water was added to each well, and the 96-well plates were incubated for $60 \mathrm{~min}$ at RT on a rotating shaker; the cell lysates were obtained by two freezing/thawing cycles. After the second cycle, the cell lysates were transferred to black microtiter plates. To the lysates was added to each sample 100 $\mu \mathrm{L}$ of a Hoechst 33258 (Sigma; 861405) working solution (20 $\mu \mathrm{g} / \mathrm{mL}$ in TNE buffer: $10 \mathrm{mM}$ Tris, $1 \mathrm{mM}$ EDTA, $2 \mathrm{M} \mathrm{NaCl}$, $\mathrm{pH}$ 7.4). The cell lysate mixtures were then incubated in the dark for $30 \mathrm{~min}$ at RT on a shaker and measured on a Perkin-Elmer VICTOR X3 multilabel plate reader (ex/em: 350/460 nm). In the FMCA assay, cells are incubated with the cell-permeant, nonfluorescent probe fluorescein diacetate (FDA) that is hydrolyzed to fluorescein by the esterase activity of cells with an intact plasma membrane, ${ }^{36,37}$ thus the emitted fluorescence is proportional to the number of viable cells. Briefly, cells cultured in 96-well microtiter plates were centrifuged for $5 \mathrm{~min}(200 \mathrm{~g})$, once washed with PBS (200 $\mu \mathrm{L} /$ well), and centrifuged once more. After aspiration of the PBS solution, $100 \mu \mathrm{L}$ of FDA working solution ( $10 \mu \mathrm{g} / \mathrm{mL}$ FDA in buffer: $125 \mathrm{mM} \mathrm{NaCl}, 25 \mathrm{mM}$ HEPES $\mathrm{pH} 7.4^{35}$ ) was added per well. Microtiter plates were incubated at $37{ }^{\circ} \mathrm{C}$ in a humidified atmosphere of $5 \% \mathrm{CO}_{2}$ for $40 \mathrm{~min}$. The quantity of released fluorescein was determined in a PerkinElmer VICTOR X3 multilabel plate reader (ex/em: 485/520 nm).

Light and Scanning Electron Microscopy (SEM). For the cytopathological examination, A549, RAW 254.7, and 3T3-L1 cells (17000, 14000 , and 10000 cells/well, respectively) were seeded in 12well culture plates on laminin-pretreated glass coverslips. After overnight incubation at $37^{\circ} \mathrm{C}$, cells were further cultured either in medium containing $2 \mu \mathrm{g} / \mathrm{mL}$ Tween 80 (control) or in medium containing NM with a surface density of $1.25 \mu \mathrm{g} \mathrm{NM} /$ $\mathrm{cm}^{2}$ corresponding approximately to $2 \mu \mathrm{g} / \mathrm{mL}$. At the end of the exposure period, generally 4 days post-exposure, the remaining cells were fixed with ice-cold $\left(-20^{\circ} \mathrm{C}\right)$ acetone/methanol $(1: 1)$ solution for $10 \mathrm{~min}$ and stained with standard hematoxyline-eosine (HE) staining solutions. For quantitative analysis of morphological alterations due to ENM treatment (Figure 7), mean values were obtained from three independent experiments. From each slide, five regions per experiment were randomly selected to count the cells.

For the scanning electron microscopy studies, A549 epithelial cells and RAW 264.7 macrophage cells grown on laminincoated glass coverslips to a semiconfluent state were treated with BNNTs at a surface density of $12.5 \mu \mathrm{g} / \mathrm{cm}^{2}(\sim 20 \mu \mathrm{g} / \mathrm{mL})$. After $96 \mathrm{~h}$ of treatment, cells were fixed with prewarmed $\left(37^{\circ} \mathrm{C}\right)$ fixation buffer containing $2.5 \%$ glutaraldehyde in $0.1 \mathrm{M} \mathrm{Na}$ cacodylate- $\mathrm{HCl}(\mathrm{pH} 7.4)$ at room temperature for $30 \mathrm{~min}$ and rinsed with $0.1 \mathrm{M} \mathrm{Na}$-cacodylate- $\mathrm{HCl}$ buffer $(\mathrm{pH} 7.4)$. The postfixation was carried out in $1 \% \mathrm{OsO}_{4}$ for 20 min; cells were dehydrated through graded ethanol concentrations. Once in $100 \%$ ethanol, the mounted cells were dried in $\mathrm{CO}_{2}$ (at a critical point) (Balzers Device CPD 020), mounted on aluminum sample holders, and sputter-coated with gold/palladium in a Baltec MED020 sputter coater. The cells were imaged with a FEI XL30 SFEG high-resolution scanning electron microscope; micrographs were taken with an acceleration voltage of $1 \mathrm{kV}$.

Acknowledgment. L.H. thanks the Swiss National Foundation (Project Number: 205321-125299/1) for the support. D.G., C. Z., and Y.B. thank the International Center for Materials Nanoarchitectonics (MANA) of NIMS for support of the BN nanotube project. L.H. appreciates the technical assistance of Mrs. Brigitte Scolari for the sample preparation for electron 
microscopy and the help of Mrs. Fabienne Bobard for taking some of the electron micrographs.

Supporting Information Available: Figures (S1-S3) contain additional UV-vis measurements and scanning electron microscopy images.

\section{REFERENCES AND NOTES}

1. Magrez, A.; Seo, J. W.; Smajda, R.; Mionić, M.; Forró, L. Catalytic CVD Synthesis of Carbon Nanotubes: Towards High Yield and Low Temperature Growth. Materials 2010, 3, 4871-4891 and references therein.

2. Smart, S. K.; Cassady, A. I.; Lu, G. Q.; Martin, D. J. The Biocompatibility of Carbon Nanotubes. Carbon 2006, 44, 1034-1047 and references therein.

3. Jain, A. K.; Mehra, N. K.; Lodhi, N.; Dubey, V.; Mishra, D. K.; Jain, P. K.; Jain, N. K. Carbon Nanotubes and their Toxicity. Nanotoxicology 2007, 1, 167-197 and references therein.

4. Lewinski, N.; Colvin, V.; Drezek, R. Cytotoxicity of Nanoparticles. Small 2008, 4, 26-49.

5. Shvedova, A. A.; Kisin, E. R.; Porter, D.; Schulte, P.; Kagan, V. E.; Fadeel, B.; Castranova, V. Mechanisms of Pulmonary Toxicity and Medical Applications of Carbon Nanotubes: Two Faces of Janus?. Pharmacol. Ther. 2009, 121, 192-204.

6. Golberg, D.; Bando, Y.; Tang, C.; Zhi, C. Y. Boron Nitride Nanotubes. Adv. Mater. 2007, 19, 2413-2432.

7. Ciofani, G.; Raffa, V.; Menciassi, A.; Dario, P. Preparation of Boron Nitride Nanotubes Aqueous Dispersions for Biological Applications. J. Nanosci. Nanotechnol. 2008, 8, 62236231.

8. Chopra, N. G.; Luyken, R. J.; Cherrey, K.; Crespi, V. H.; Cohen, M. L.; Louie, S. G.; Zettl, A. Boron Nitride Nanotubes. Science 1995, 269, 966-967.

9. Golberg, D.; Bando, Y.; Huang, Y.; Terao, T.; Mitome, M.; Tang, C.; Zhi, C. Y. Boron Nitride Nanotubes and Nanosheets. ACS Nano 2010, 4, 2979-2993.

10. Ciofani, G.; Raffa, V.; Menciassi, A.; Cuschieri, A. Cytocompatibility, Interactions, and Uptake of PolyethyleneimineCoated Boron Nitride Nanotubes by Living Cells: Confirmation of their Potential for Biomedical Applications. Biotechnol. Bioeng. 2008, 101, 850-858.

11. Ciofani, G.; Raffa, V.; Yu, J.; Chen, Y.; Obata, Y.; Takeoka, S.; Menciassi, A.; Cuschieri, A. Boron Nitride Nanotubes: A Novel Vector for Targeted Magnetic Drug Delivery. Curr. Nanosci. 2009, 5, 33-38.

12. Ciofani, G.; Danti, S.; D'Alessandro, D.; Moscato, S.; Menciassi, A. Assessing Cytotoxicity of Boron Nitride Nanotubes: Interference with the MTT Assay. Biochem. Biophys. Res. Commun. 2010, 394, 405-411.

13. Ciofani, G.; Ricotti, L.; Danti, S.; Moscato, S.; Nesti, C.; D'Alessandro, D.; Dinucci, D.; Chiellini, F.; Pietrabissa, A.; Petrini, $M_{\text {; }}$ et al. Investigation of Interactions between Poly-L-lysine-Coated Boron Nitride Nanotubes and $\mathrm{C}_{2} \mathrm{Cl}_{2}$ Cells: Up-take, Cytocompatibility, and Differentiation. Int. J. Nanomed. 2010, 5, 285-298.

14. Chen, X.; Wu, P.; Rousseas, M.; Okawa, D.; Gartner, Z.; Zettl, A.; Bertozzi, C. R. Boron Nitride Nanotubes Are Noncytotoxic and Can Be Functionalized for Interaction with Proteins and Cells. J. Am. Chem. Soc. 2009, 131, 890-891.

15. Horváth, L.; Magrez, A.; Forró, L.; Schwaller, B. Cell Type Dependence of Carbon Based Nanomaterial Toxicity. Phys. Status Solidi B 2010, 247, 3059-3062.

16. Magrez, A.; Kasas, S.; Salicio, V.; Pasquier, N.; Seo, J. W.; Celio, M.; Catsicas, S.; Schwaller, B.; Forró, L. Cellular Toxicity of Carbon-Based Nanomaterials. Nano Lett. 2006, 6, 1121-1125.

17. Worle-Knirsch, J. M.; Pulskamp, K.; Krug, H. F. Oops They Did It Again! Carbon Nanotubes Hoax Scientists in Viability Assays. Nano Lett. 2006, 6, 1261-1268.

18. Magrez, A.; Horváth, L.; Smajda, R.; Salicio, V.; Pasquier, N.; Forró, L.; Schwaller, B. Cellular Toxicity of $\mathrm{TiO}_{2}$-Based Nanofilaments. ACS Nano 2009, 3, 2274-2280.
19. Ciofani, G.; Danti, S.; D'Alessandro, D.; Ricotti, L.; Moscato, S.; Bertoni, G.; Falqui, A.; Berrettini, S.; Petrini, M.; Mattoli, V.; et al. Enhancement of Neurite Outgrowth in NeuronalLike Cells Following Boron Nitride Nanotube-Mediated Stimulation. ACS Nano 2010, 4, 6267-6277.

20. Yazdi, A. S.; Guarda, G.; Riteau, N.; Drexler, S. K.; Tardivel, A.; Couillin, I.; Tschopp, J. Nanoparticles Activate the NLR Pyrin Domain Containing 3 (NIrp3) Inflammasome and Cause Pulmonary Inflammation through Release of IL-10 and IL-1 $\beta$. Proc. Natl. Acad. Sci. U.S.A. 2010, 107, 1944919454.

21. Lahiri, D: Rouzaud, F. Richard, T. Keshri, A. K. Bakshi, S. R Kos, L.; Agarwal, A. Boron Nitride Nanotube Reinforced Polylactide-Polycaprolactone Copolymer Composite: Mechanical Properties and Cytocompatibility with Osteoblasts and Macrophages In Vitro. Acta Biomater. 2010, 6, 3524-3533.

22. Lahiri, D.; Singh, V.; Benaduce, A. P.; Seal, S.; Kos, L.; Agarwal, A. Boron Nitride Nanotube Reinforced Hydroxyapatite Composite: Mechanical and Tribological Performance and In-Vitro Biocompatibility to Osteoblasts. J. Mech. Behav. Biomed. Mater. 2011, 4, 44-56.

23. Zhi, C. Y.; Bando, Y.; Tang, C. C.; Golberg, D. Effective Precursor for High Yield Synthesis of Pure BN Nanotubes. Solid State Commun. 2005, 135, 67-70.

24. Gao, Z.; Zhi, C. Y.; Bando, Y.; Golberg, D.; Serizawa, T. Isolation of Individual Boron Nitride Nanotubes via Peptide Wrapping. J. Am. Chem. Soc. 2010, 132, 4976-4977.

25. Zhi, C. Y.; Zhang, L.; Bando, Y.; Terao, T.; Tang, C.; Kuwahara, $\mathrm{H} . ;$ Nitride Nanotubes in Polyaniline. J. Phys. Chem. C 2008, 112, 17592-17595.

26. Zhi, C. Y.; Bando, Y.; Wang, W.; Tang, C.; Kuwahara, $\mathrm{H}_{\text {; }}$ Golberg, D. Molecule Ordering Triggered by Boron Nitride Nanotubes and "Green" Chemical Functionalization of Boron Nitride Nanotubes. J. Phys. Chem. C 2007, 111 , 18545-18549.

27. Zhi, C. Y.; Bando, Y.; Tang, C.; Honda, S.; Sato, K.; Kuwahara, H.; Golberg, D. Purification of Boron Nitride Nanotubes through Polymer Wrapping. J. Phys. Chem. B 2006, 110, 1525-1528.

28. Tatsuishi, T.; Oyama, Y.; Iwase, K.; Yamaguchi, J. Y.; Kobayashi, M.; Nishimura, Y.; Kanada, A.; Hirama, S. Polysorbate 80 Increases the Susceptibility to Oxidative Stress in Rat Thymocytes. Toxicology 2005, 207, 7-14.

29. Wick, P.; Manser, P.; Limbach, L. K.; Dettlaff-Weglikowska, U.; Krumeich, F.; Roth, S.; Stark, W. J.; Bruinink, A. The Degree and Kind of Agglomeration Affect Carbon Nanotube Cytotoxicity. Toxicol. Lett. 2007, 168, 121-131.

30. Tabet, L.; Bussy, C.; Amara, N.; Setyan, A.; Grodet, A.; Rossi, M. J.; Pairon, J. C.; Boczkowski, J.; Lanone, S. Adverse Effects of Industrial Multiwalled Carbon Nanotubes on Human Pulmonary Cells. J. Toxicol. Environ. Health A 2009, 72, 60-73.

31. $\mathrm{Ye}, \mathrm{S}, \mathrm{F} \cdot \mathrm{Wu}, \mathrm{Y}, \mathrm{H} ; \mathrm{Hou}, \mathrm{Z}, \mathrm{Q}$; Zhang, $\mathrm{O}, \mathrm{Q}$. ROS and NF- $\kappa \mathrm{B}$ are involved in Upregulation of IL-8 in A549 Cells Exposed to Multi-walled Carbon Nanotubes. Biochem. Biophys. Res. Commun. 2009, 379, 643-648.

32. Garza, K. M.; Soto, K. F.; Murr, L. E. Cytotoxicity and Reactive Oxygen Species Generation from Aggregated Carbon and Carbonaceous Nanoparticulate Materials. Int. J. Nanomed. 2008, 3, 83-94.

33. Pulskamp, K.; Diabaté, S.; Krug, H. F. Carbon Nanotubes Show No Sign of Acute Toxicity but Induce Intracellular Reactive Oxygen Species in Dependence on Contaminants. Toxicol. Lett. 2007, 168, 58-74.

34. Rago, R.; Mitchen, J.; Wilding, G. DNA Fluorometric Assay in 96-Well Tissue Culture Plates Using Hoechst 33258 after Cell Lysis by Freezing in Distilled Water. Anal. Biochem. 1990, 191, 31-34.

35. Lindhagen, E.; Nygren, P.; Larsson, R. The Fluorometric Microculture Cytotoxicity Assay. Nat. Protoc. 2008, 3 1364-1369.

36. Larsson, R.; Kristensen, J.; Sandberg, C.; Nygren, P. Laboratory Determination of Chemotherapeutic Drug Resistance in Tumor Cells from Patients with Leukemia, Using a 
Fluorometric Microculture Cytotoxicity Assay (FMCA). Int. J. Cancer 1992, 50, 177-185.

37. Rubinstein, L. V.; Shoemaker, R. H.; Paull, K. D.; Simon, R. M.; Tosini, S.; Skehan, P.; Scudiero, D. A.; Monks, A; Boyd, M. R. Comparison of In Vitro Anticancer-Drug-Screening Data Generated with a Tetrazolium Assay versus a Protein Assay against a Diverse Panel of Human Tumor Cell Lines. J. Natl. Cancer Inst. 1990, 82, 1113-1118. 